Article

\title{
Improved As-Synthesized Oleic Amido Propyl Betaine Surfactant Mixture for Stable Ultra-Low Interfacial Tension: Effect of Mixed Co-Solvents
}

\author{
Norhidayah Ahmad Wazir 1,2,*(D), Wasan Saphanuchart ${ }^{1}$, Anita Ramli ${ }^{2, *(\mathbb{D})}$ and Nurida Yusof ${ }^{1}$ \\ 1 Group Research and Technology, Petronas Research Sdn Bhd, Bangi, Kajang 43000, Selangor, Malaysia; \\ wasan.saphanuchart@petronas.com.my (W.S.); nuridayusof@petronas.com.my (N.Y.) \\ 2 Department of Fundamental and Applied Science, Universiti Teknologi PETRONAS, \\ Bandar Seri Iskandar 32610, Perak, Malaysia \\ * Correspondence: hidayah_wazir@petronas.com.my (N.A.W.); anita_ramli@utp.edu.my (A.R.)
}

Citation: Wazir, N.A.; Saphanuchart, W.; Ramli, A.; Yusof, N. Improved As-Synthesized Oleic Amido Propyl Betaine Surfactant Mixture for Stable Ultra-Low Interfacial Tension: Effect of Mixed Co-Solvents. Colloids Interfaces 2021, 5, 2. https://doi.org/ 10.3390/colloids5010002

Received: 1 November 2020 Accepted: 11 December 2020 Published: 6 January 2021

Publisher's Note: MDPI stays neutral with regard to jurisdictional clai$\mathrm{ms}$ in published maps and institutional affiliations.

Copyright: (C) 2021 by the authors. Licensee MDPI, Basel, Switzerland. This article is an open access article distributed under the terms and conditions of the Creative Commons Attribution (CC BY) license (https:// creativecommons.org/licenses/by/ $4.0 /)$.

\begin{abstract}
As-synthesized oleic amido propyl betaine surfactant mixture, that was produced through a "direct formulation through synthesis" process, exhibited ultra-low oil/water interfacial tension (IFT) values as low as $3.5 \times 10^{-4} \mathrm{mN} / \mathrm{m}$ when dissolved in seawater at a reservoir temperature of $96{ }^{\circ} \mathrm{C}$. The as-synthesized surfactant, which was left untreated, had a slightly cloudy appearance when mixed with seawater. Polar solvents were introduced to this surfactant to improve its aqueous solubility by changing its overall hydrophilicity, particularly on the oil/water interface. In this study, two types of glycol ether co-solvent, i.e., ethylene glycol monobutyl ether and diethylene glycol monobutyl ether, were used at different concentrations in a single application and as a mixture of co-solvents at a certain ratio. The behavior of the as-synthesized surfactant with the presence of these co-solvents was investigated. As a result, it showed that the co-solvent helps in solubility improvement and alters the interfacial tension behavior of the surfactant. Ethylene glycol monobutyl ether was found to be efficient in maintaining an ultra-low IFT value of the surfactant. However, the aqueous solubility of the surfactant was not significantly improved. In contrast, the addition of diethylene glycol monobutyl ether showed improvement of the aqueous solubility of the surfactant, but it tends to increase the IFT above ultra-low value. Based on this understanding, a set of cosolvent mixing ratios were tested, and the results showed further improvement in both the oil/water interfacial tension behavior and surfactant aqueous solubility. The most stable oil/water IFT of $3.36 \times 10^{-3} \mathrm{mN} / \mathrm{m}$ and clearer surfactant solutions were obtained for ratio $\mathrm{C}$ at $35 \mathrm{wt}$.\% presence of co-solvent.
\end{abstract}

Keywords: ultra-low IFT; co-solvent; EOR surfactant

\section{Introduction}

In the enhanced oil recovery (EOR) method, surfactant flooding is one of the most efficient ways to improve oil displacement from a depleted reservoir. Surfactant was added to the oil/water system, and the interfacial tension between the water and oil was reduced to a certain level that should be enough to displace the trapped oil. For greater performance of the chemical oil displacement system in EOR, its important index of interfacial tension (IFT) is preferred to be at an ultra-low level $\left(10^{-3} \mathrm{mN} / \mathrm{m}\right.$ order of magnitudes [1] Extensive research has been done worldwide to search for the best surfactant for the said application [2-4]. Among the most applied are anionic and amphoteric types with carboxylate and sulfonate heads, especially for high-temperature applications [5].

Amphoteric surfactant is one of the surfactants that has been studied worldwide for applicability in EOR. In the study done by [6], it was found that amphoteric surfactant produced the most ultra-low IFT value out of 30 surfactants that were synthesized. In our lab, oleic amido propyl betaine was synthesized using a modified synthesized step, 
which could produce ultra-low IFT when applying directly with seawater at a high temperature $\left(96^{\circ} \mathrm{C}\right)$. The uniqueness of this surfactant is that it was produced through a "direct formulation through synthesis" which did not require any further treatment processes to purify the surfactant, yet the surfactant would still be able reduce the crude oil/water IFT. Through a characterization process, it was clear that the surfactant still contained some unreacted components and by-products. However, the presence of those unwanted components influenced the interface behavior of the surfactant and reduced the IFT to an ultra-low level [7]. Apart from the surfactant's activity at the interface, it is also crucial to consider the aqueous solubility of the surfactant. especially in seawater, as many factors can affect the aqueous solubility of the surfactant such as the presence of divalent ions $\left(\mathrm{Ca}^{2+}, \mathrm{Mg}^{2+}\right)$, the length of hydrophobic surfactant tail, the nature of the surfactant head group, the electrical charge of the surfactant counterion, temperature, and the solution environment [8].

Co-solvents are typically used in surfactant formulation to increase the compatibility between surfactants and the aqueous phase, allowing for a clear and stable surfactant slug. This criterion is essential to ensure the injected solution will transport in the reservoir over long distances with low retention [9]. They are usually amphiphiles that have the ability to partition into aqueous, oleic, and microemulsion phases, thus allowing alteration of the phase behavior [10]. In this work, we aimed to enhance the as-synthesized surfactant's property by adding a co-solvent to improve the solubility with its long hydrophobic tail and the presence of unreacted elements. This study aimed to show that the surfactant, containing some unreacted components, can be improved for more stable performance in terms of the IFT, solubility of the surfactant in seawater, and the microemulsion phase behavior. Enhancement of the as-synthesized surfactant was performed by the addition of polar co-solvents from the glycol ether family, which are ethylene glycol mono butyl ether (EGME) and diethylene glycol mono butyl ether (DGME). The function of the co-solvents was to reduce the formation of viscous structures such as gels, liquid crystals, and macroemulsions [11]. These two co-solvents were selected due to their high boiling points of 170 and $230{ }^{\circ} \mathrm{C}$, for EGME and DGME, respectively, as well as slow evaporating properties, suitable for high-temperature applications. Consideration of the higher carbon number of the surfactant tail was also taken into account, which may desire more hydrophilic co-solvents to solubilize the oil, leading to an equal partitioning of the surfactant in oil and brine [10,12]. EGME and DGME are among the most popular co-solvents in EOR studies and have been used to increase surfactant solubility under high-salinity conditions to overcome the salting-out effect $[13,14]$ and as surfactant/co-surfactant to improve microemulsion as well as functioning as an additive in alkaline surfactant polymer (ASP) optimization in EOR application $[15,16]$. It is also noted that the ether type of co-solvents also has a surface-active agent property and is thermally stable [13].

\section{Materials and Methods}

\subsection{Materials Used}

The surfactant used in this study was reported in a previous publication [7]. The assynthesized surfactant was used without further treatment. Actual crude oil from one Malaysian field (Field A) was used in this study, with a composition of $8.4 \%$ volatiles, $47.61 \%$ inorganics, $44.4 \%$ aromatics, and $0.7 \%$ resins. The total acid number, specific gravity, and kinematic viscosity of the oil were found to be $1.064 \mathrm{mg} \mathrm{KOH} / \mathrm{g}, 0.806$, and $96 \mathrm{~mm}^{2} / \mathrm{s}$ at $45^{\circ} \mathrm{C}$, respectively. Synthetic seawater according to the Field A seawater composition was prepared by mixing different salts $\left(\mathrm{NaCl}, 42.33 \mathrm{~g} / \mathrm{L} ; \mathrm{KCl}, 1.48 \mathrm{~g} / \mathrm{L} ; \mathrm{CaCl}_{2}, 2.43 \mathrm{~g} / \mathrm{L}\right.$; $\left.\mathrm{MgCl}_{2}, 19.46 \mathrm{~g} / \mathrm{L} ; \mathrm{Na}_{2} \mathrm{SO}_{4}, 7.09 \mathrm{~g} / \mathrm{L} ; \mathrm{SrCl}_{2}, 0.039 \mathrm{~g} / \mathrm{L} ; \mathrm{KCl}, 1.48 \mathrm{~g} / \mathrm{L} ; \mathrm{NaHCO}_{3}, 0.311 \mathrm{~g} / \mathrm{L}\right)$ in deionized water. All chemicals for the synthetic seawater preparation were purchased from Merck, with $98 \%$ purity. 


\subsection{Improvement of As-Synthesized Amphoteric Surfactant for Better Solubility and Stability}

The as-synthesized surfactant was prepared as a $25 \mathrm{wt} . \%$ active concentration in deionized water. The surfactant was diluted to different concentrations ranging from 0.1 to $0.5 \mathrm{wt} . \%$ by using synthetic seawater with $30,000 \mathrm{ppm}$ salinity, and the solubility of surfactant was observed accordingly. The solubility of the surfactant was enhanced with glycol ether co-solvent. For this study, two types of co-solvents were used, i.e., ethylene glycol monobutyl ether (EGME) and diethylene glycol methyl butyl ether (DGME). The cosolvent was added into $25 \mathrm{wt} . \%$ of the semi-solid surfactant at various concentrations, starting from 3 to $40 \mathrm{wt} . \%$, and deionized water was added to $100 \mathrm{wt} . \%$. The solution was stirred at a slow speed between 60 and $80 \mathrm{rpm}$ at $50{ }^{\circ} \mathrm{C}$ for $30 \mathrm{~min}$. The mixture was further diluted in seawater to $0.1 \mathrm{wt} . \%$ as a screening concentration. This concentration was selected based on the IFT performance of as-synthesized surfactant without co-solvent, which gave the IFT value of $3.4 \times 10^{-4} \mathrm{mN} / \mathrm{m}$ [7]. The samples were then tested for the IFT analysis.

\subsection{Co-Solvent Ratio Study}

The effect of the co-solvent ratio was also tested. The co-solvent that gave good solubility and IFT value at a specific amount in the first test was selected and mixed into the surfactant to study the best ratio. The ratios of 1:1 (A), 3:1 (B), 4:1 (C), and 6:1 (D) were used, which represent the ratio of EGME: DGME and were prepared at selected concentrations of co-solvent. In this test, the surfactant solution appearance and IFT were monitored, and a microemulsion phase behavior test was also performed for the selected ratio to determine the type of microemulsion produced.

\subsection{Turbidity Test}

A turbidity meter model HACH TL2350 Tungsten Lamp Turbidimeter, EPA, 0-10,000 nepholometric turbidity unit (NTU) was used to measure the turbidity level of the solution. In each experiment, a sample volume of approximately $20 \mathrm{~mL}$ was used and was placed in a $25-\mathrm{mm}$ sample cell. The experiment was performed at room temperature $\left(25^{\circ} \mathrm{C}\right)$.

\subsection{Oil-Water Interfacial Tension Test}

The oil-water IFT of the prepared surfactant solution was measured using a Data Physics spinning drop tensiometer, model SVT 20N, equipped with a video measuring system (USB-CCIR camera; max. resolution, $768 \times 576$ pixels; max. frame rate, 123 frames $/ \mathrm{s}$ ) at $96{ }^{\circ} \mathrm{C}$ for $60 \mathrm{~min}$ with an interval of $5 \mathrm{~min}$ between each reading. In this test, the crude oil drop was injected into a capillary tube containing the surfactant solution. The capillary tube was rotated at $4000 \mathrm{rpm}$, and the value of the dynamic IFT was monitored through the images.

\subsection{Microemulsion Phase Behavior Test}

A volume of $4 \mathrm{~mL}$ with a ratio of 1:1 of surfactant and crude oil was filled into a small test tube with a dimension of $7.0 \mathrm{~mm}$ outer diameter) $\times 4.8 \mathrm{~mm}$ (Internal diameter) $\times 270 \mathrm{~mm}$ (Length) $\times 1.0 \mathrm{~mm}$. The test tubes were adequately sealed with chemicalresistant epoxy resin that can withstand high temperatures and were shaken moderately by tilting 100 times before they were put in the oven at $96^{\circ} \mathrm{C}$. The samples were taken out, and the appearance of the liquid samples was monitored until it reached 14 days. The microemulsion phase behavior type was recorded.

\section{Results and Discussions}

\subsection{Solubility and Interfacial Tension of As-Synthesized Surfactants in Seawater}

The solubility of the as-synthesized surfactant (ULCB) solution was tested at various concentrations against seawater at ambient temperature. The as-synthesized surfactant dissolved directly in seawater upon completion of the synthesis had a slightly hazy appearance. This condition was anticipated to occur as the as-synthesized surfactant still had 
remaining by-products. Generally, the surfactants made of long carbon chains had less solubility in water as compared to those with shorter ones due to the higher hydrophobicity [17]. Apart from the hydrophobicity or the polarity, the solubility of the surfactant in seawater could also be affected by saline water due to the salting-in/salting-out effect [18] It was observed through the appearance of this surfactant that it had good solubility and clarity in distilled water; however, it became cloudy when the actual composition of seawater was used due to the divalent ions such as calcium and magnesium ions that were naturally present in seawater, as shown in Figure 1 below for the concentrations from 0.05 to $0.5 \mathrm{wt} . \%$. The turbidity of each concentration was tested and was tabulated in the Table 1 below.

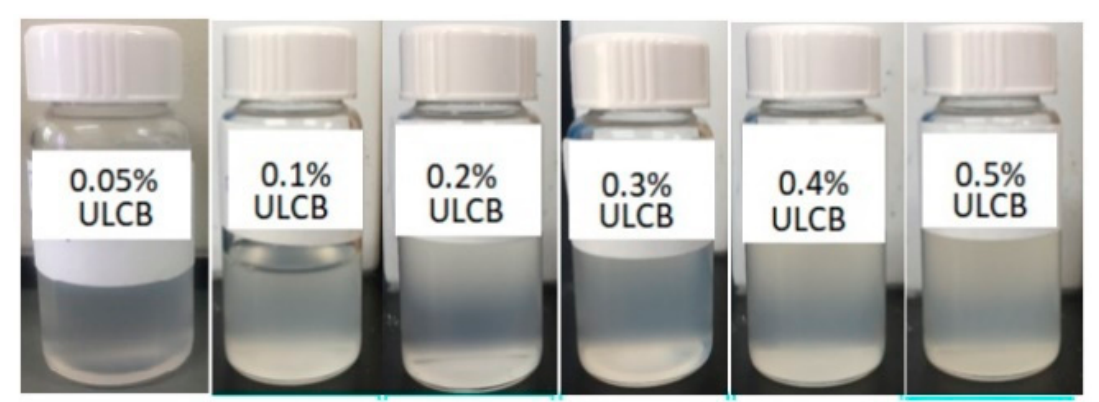

Figure 1. As-synthesized surfactant (ULCB) when diluted at different concentrations in seawater.

Table 1. Turbidity value for as-synthesized surfactant.

\begin{tabular}{cc}
\hline Concentration (\%) & Turbidity (NTU) \\
\hline 0.05 & 79.5 \\
\hline 0.1 & 149.4 \\
\hline 0.2 & 189.9 \\
\hline 0.3 & 234.2 \\
\hline 0.4 & 308.8 \\
\hline 0.5 & 316.2 \\
\hline
\end{tabular}

An IFT test was performed for the as-synthesized surfactant diluted in Field A seawater. For the diluted surfactant without co-solvent, the crude oil/water IFT values at $96{ }^{\circ} \mathrm{C}$ with surfactant concentrations of 0.05 to $0.5 \mathrm{wt} . \%$ are presented in Figure 2. The lowest value of IFT was recorded at $0.1 \mathrm{wt} . \%$ with a value of $3.4 \times 10^{-4} \mathrm{mN} / \mathrm{m}$ at $60 \mathrm{~min}$ of the evaluation. This concentration is slightly higher than the critical micelle concentration (CMC) of this surfactant, which was determined at $0.05 \mathrm{wt} . \%$ through the surface tension method in the previous work [7], thus indicating that the surfactant solution had enough concentration to form a dense packing at the interface that was consequently reducing the IFT to the ultra-low level. At this concentration, however, the dynamic IFT showed some instability, which might be due to the back-and-forth mechanism of surfactant diffusion from the bulk to the crude oil/seawater interface and the diffusion of surfactant back into the bulk solution $[19,20]$. This phenomenon is driven by the adsorption of the surfactant monomer, which started at the empty site until the interface became fuller and more surfactant monomer arrived at the occupied site, which subsequently induced the back-diffusion of the surfactant to the bulk solution [21] until it reaches an equilibrium before $60 \mathrm{~min}$. Ultra-low IFT was also observed at 0.2 and $0.4 \mathrm{wt} . \%$ surfactant concentrations with the values of $6.36 \times 10^{-3}$ and $6.41 \times 10^{-3} \mathrm{mN} / \mathrm{m}$, respectively. As the lowest IFT was found for the solution with $0.1 \mathrm{wt} . \%$, this concentration was chosen as the screening concentration for the improvement of the surfactant with the co-solvent. 


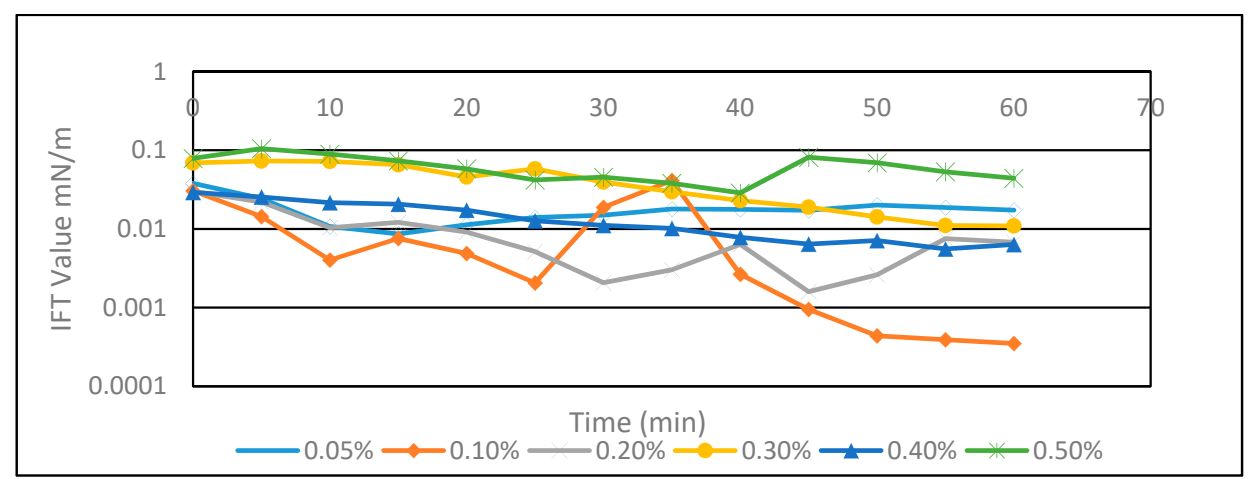

Figure 2. Crude oil-seawater IFT results for $0.05-0.5 \mathrm{wt} . \%$ of as-synthesized surfactant in seawater as published in [7].

\subsection{The Effect of Co-Solvent on Solubility and IFT}

A high carbon number in the surfactant tail can affect the solubility of the surfactant. The addition of a co-solvent with high polarity property is proven to enhance the miscibility of organic compounds in water, thus improving the solubility of the solution. [22]. In this study, two types of glycol ether-based co-solvents were tested: ethylene glycol monobutyl ether and diethylene glycol monobutyl ether. These two solvents are common in EOR application [13], and they were selected due to their high polarity property, high boiling point, and slow evaporation, which are suitable for high-temperature applications. The stability of the surfactant was determined through the surfactant's ability to maintain solution clarity without phase separation and precipitation. The addition of co-solvents was also expected to improve the dynamic IFT behavior while retaining ultra-low IFT.

Both ethylene glycol ether solvents are easily dissolved in water because they consist of a hydroxyl group attached to the terminal carbon and ether group in between, allowing more hydrogen bonding with the water molecules [19]. After mixing with the solvent, the amount of polar groups increased in the solution, making the magnitude of the hydrophobic effect smaller [23]. Hence, with higher concentrations of co-solvent used, the solubility of surfactants also increased due to more polar sites introduced, allowing for hydrogen bonding between the hydrophilic group in the co-solvent and surfactant with water. In this study, the surfactant solutions were prepared by diluting the solution to $0.1 \mathrm{wt} . \%$ in seawater from the mixture of surfactant with co-solvent. The appearance of the surfactant in the seawater was found improved as it was more transparent and stable as the concentration of the co-solvent increased from 3 to $40 \mathrm{wt} . \%$, as shown in Figures 3 and 4. The turbidity level of the surfactant solution also tremendously dropped from 149.4 NTU at $0.1 \mathrm{wt} \%$ in the as-synthesized surfactant to below $70 \mathrm{NTU}$ with the presence of co-solvent.

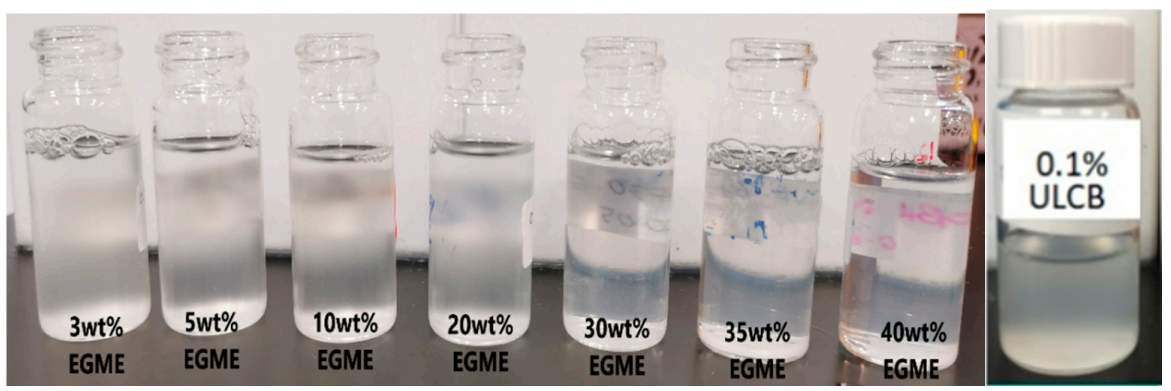

Figure 3. Solubility of surfactant mixture with different co-solvent concentration diluted to 0.1 wt.\% in seawater with ethylene glycol mono butyl ether (EGME) at 3, 5, 10, 20, 30, 35, and 40 wt.\% compared to $0.1 \mathrm{wt} . \%$ as-synthesized surfactant in seawater (ULCB). 


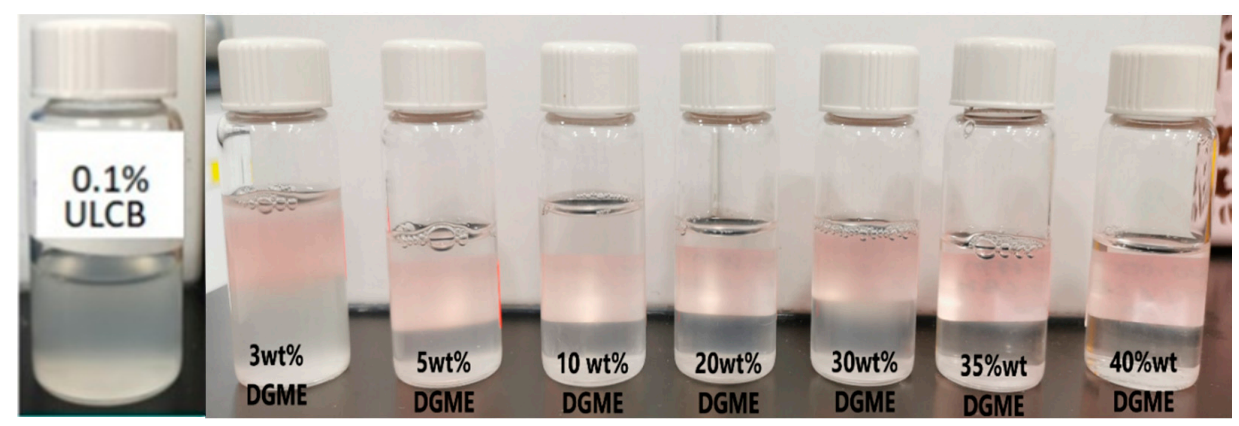

Figure 4. Solubility of $0.1 \mathrm{wt}$.\% surfactant with 3, 5, 10, 20, and $30 \mathrm{wt} . \%$ diethylene glycol mono butyl ether (DGME) compared to $0.1 \mathrm{wt}$ \% as-synthesized surfactant in seawater (ULCB).

The $0.1 \mathrm{wt} . \%$ surfactant mixed with EGME in seawater was found to be clearer as compared to the $0.1 \mathrm{wt} . \%$ as-synthesized surfactant in seawater, as can be seen in Figure 1. The surfactant-co-solvent solution stability was monitored for $24 \mathrm{~h}$ at a room temperature of $25^{\circ} \mathrm{C}$. As a result, only surfactants with 20 to $40 \mathrm{wt}$.\% EGME were selected as they showed a better appearance upon mixing with seawater and after being left at room temperature. The level turbidity of each sample is presented in Table 2

Table 2. Turbidity values for as-synthesized surfactant with the presence of EGME at different concentrations.

\begin{tabular}{cc}
\hline Concentration (\%) & Turbidity (NTU) \\
\hline 3 & 69.5 \\
\hline 5 & 64.1 \\
\hline 10 & 59.2 \\
\hline 20 & 48.2 \\
\hline 30 & 44.5 \\
\hline 35 & 33.5 \\
\hline 40 & 34.4 \\
\hline
\end{tabular}

The solubility and stability of the as-synthesized surfactant were also tested with DGME. This co-solvent theoretically has a better solvency effect due to the nature of its structure of having two ether groups, which increases the polarity of the component. By applying this co-solvent, the solution compatibility of the surfactant was improved as the surfactant solution becomes even more clearer immediately after it was mixed with seawater, especially at the concentration of $20-40 \mathrm{wt} . \%$ as can be seen in Figure 4 . Hence, these concentrations were selected for the IFT screening. The turbidity value, which indicated a reduction in value as more concentration of co solvent added, is shown in Table 3 below:

Table 3. Turbidity value for as-synthesized surfactant with the presence of DGME.

\begin{tabular}{cc}
\hline Concentration (\%) & Turbidity (NTU) \\
\hline 3 & 40.8 \\
\hline 5 & 40.2 \\
\hline 10 & 38.1 \\
\hline 20 & 34.1 \\
\hline 30 & 28.5 \\
\hline 35 & 23.7 \\
\hline 40 & 23.4 \\
\hline
\end{tabular}


Figure 5 shows the dynamic IFT data for the $25 \mathrm{wt} . \%$ as-synthesized surfactant with the addition of 20 to $40 \mathrm{wt} . \%$ co-solvent diluted in seawater at a $0.1 \mathrm{wt} . \%$ concentration. These concentrations were selected for the IFT analysis due to their stability after $24 \mathrm{~h}$ in seawater. The dynamic IFT analysis shows that all co-solvents increased the original IFT value of the as-synthesized surfactant. After $60 \mathrm{~min}$, the lowest IFT value was found for the surfactant with the addition of $30 \mathrm{wt} . \%$ EGME solvent with the value of $0.00459 \mathrm{mN} / \mathrm{m}$, while for the $30 \mathrm{wt} . \%$ DGME, the IFT value was recorded as $0.01487 \mathrm{mN} / \mathrm{m}$. In this test, it was observed that EGME still maintained the ultra-low IFT value of the surfactant as compared to DGME. The structure of EGME itself, which has a lower carbon number $\left(\mathrm{C}_{6} \mathrm{H}_{14} \mathrm{O}_{2}\right)$ as compared to DGME $\left(\mathrm{C}_{8} \mathrm{H}_{18} \mathrm{O}_{3}\right)$, might contribute in its better adjustment of the hydrophilic-lipophilic balance of the surfactant [24], thus allowing for more packing adsorption at the interface of oil/seawater. For other co-solvent concentrations, at 20, 35 , and $40 \mathrm{wt} . \%$, the IFT values did not show significant improvements. However, they stabilized the activity of the as-synthesized surfactant mixture at the interface and made it dynamically stable during the entire experimental period. The trend was obtained for both EGME and DGME solutions, as tabulated in Table 4. Thus, the concentrations of 30 and $35 \mathrm{wt} . \%$ of both co-solvents were chosen for further analysis due to the stability in seawater and the low IFT values.

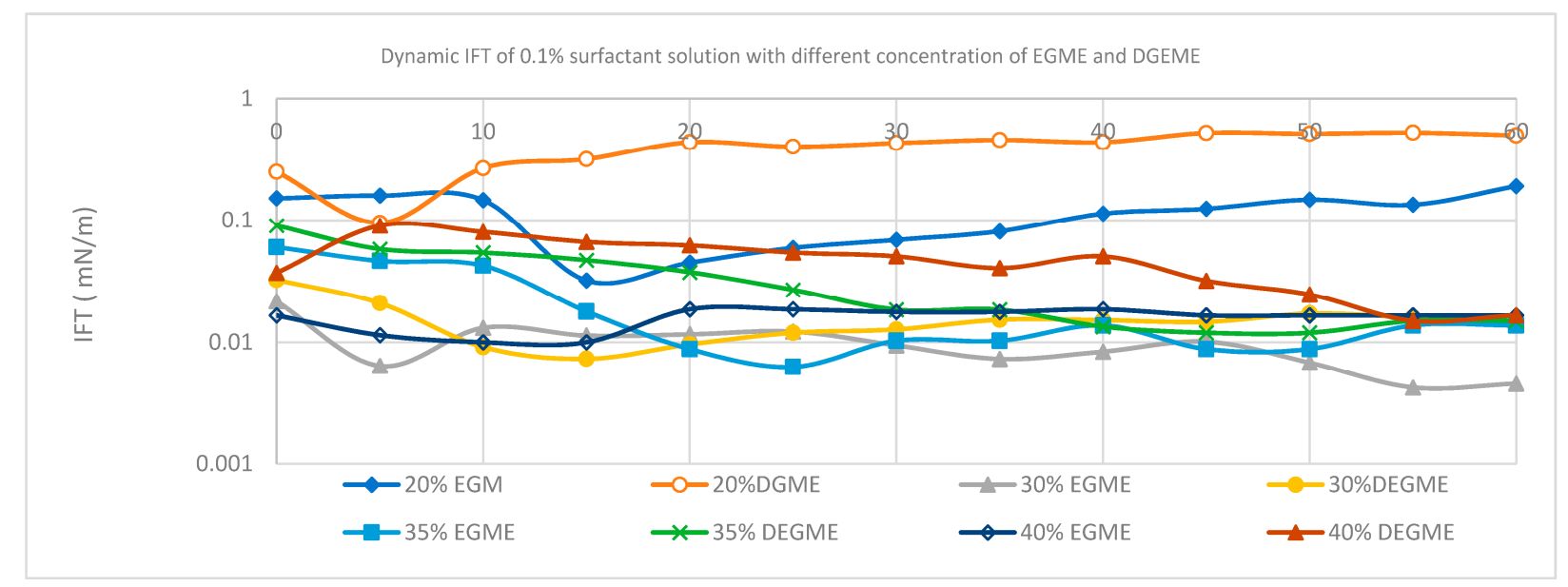

Figure 5. Interfacial tension (IFT) results for surfactant with 20 to $40 \mathrm{wt} \%$ of co-solvent addition diluted in seawater at 0.1 wt. \% concentration.

Table 4. IFT values at $60 \mathrm{~min}$ with different concentrations of co-solvent in the surfactant-co-solvent mixture.

\begin{tabular}{ccc}
\hline Concentration (wt. $\%)$ & Co-Solvent & IFT (m/N/m) at $\mathbf{6 0 ~} \mathbf{~ m i n}$ \\
\hline \multirow{2}{*}{20} & EGME & 0.19126 \\
\cline { 2 - 3 } & DGME & 0.49966 \\
\cline { 2 - 3 } 30 & EGME & 0.00459 \\
\hline \multirow{2}{*}{35} & DGME & 0.01487 \\
\cline { 2 - 3 } & EGME & 0.01371 \\
\hline \multirow{2}{*}{40} & DGME & 0.01490 \\
\cline { 2 - 3 } & EGME & 0.01850 \\
\hline
\end{tabular}

\subsection{Effect of Mixed Solvents on the IFT of the Surfactant}

Further testing was carried out to see the solvent mixture's effect after the individual solvent enhanced the IFT value and solubility. Four different ratios were used where the amount of EGME was added more compared to DGME to maintain the solubility 
in seawater. In this study, only 30 and $35 \mathrm{wt} . \%$ co-solvent content was tested. Out of all combinations, only ratio A (1:1) with $30 \mathrm{wt} . \%$ co-solvent content did not reach the ultra-low value after $60 \mathrm{~min}$. The other ratios were able to reach the ultra-low level after at least $45 \mathrm{~min}$, as shown in Figure 6. The addition of a co-solvent mixture was observed to further reduce the IFT and improve the surfactant's stability compared to single co-solvent application. The combination of DGME with EGME seems to have a good synergy in reducing the IFT and enhanced the stability of the surfactant in seawater. To determine the best combination ratio, EGME was added in increasing amounts compared to the DGME due to its IFT reduction effect, while at the same time, the DGME is needed for the solubility and clarity of the sample. In terms of the amount, $35 \mathrm{wt} . \%$ solvent performed better than the $30 \mathrm{wt} . \%$ addition of co-solvent, which was observed through excellent solubility and maintaining ultra-low IFT. Although the $30 \mathrm{wt} . \%$ ratio of the solvent mixtures showed the lowest IFT (Figure 6), the surfactant with $35 \mathrm{wt} . \%$ co-solvent ratio exhibited better performance in terms of clarity and stability. From the $35 \mathrm{wt} . \%$ co-solvent combination, ratio $C$ was found as the best combination due to the shortest time until an equilibrium was achieved, with the ultra-low IFT obtained as early as $15 \mathrm{~min}$, as shown in Figure 7. To further qualify the surfactant, a phase behavior study was performed for the surfactant at $35 \mathrm{wt} . \%$ at different ratios. The results are presented in the next section.

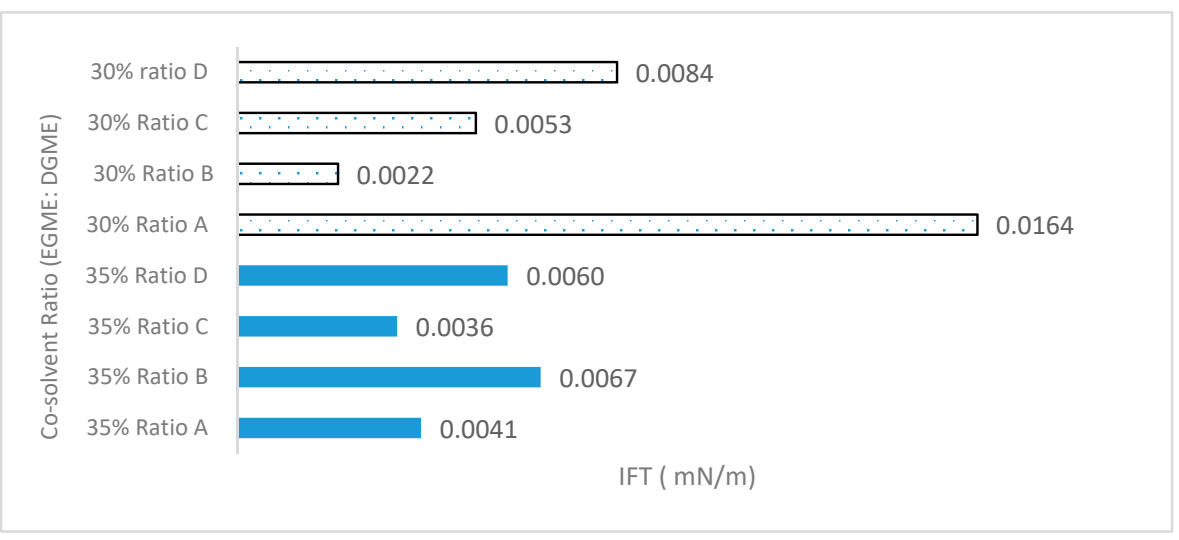

Figure 6. IFT at $60 \mathrm{~min}$ with as-synthesized surfactant in the presence of EGME/DGME at different ratios.

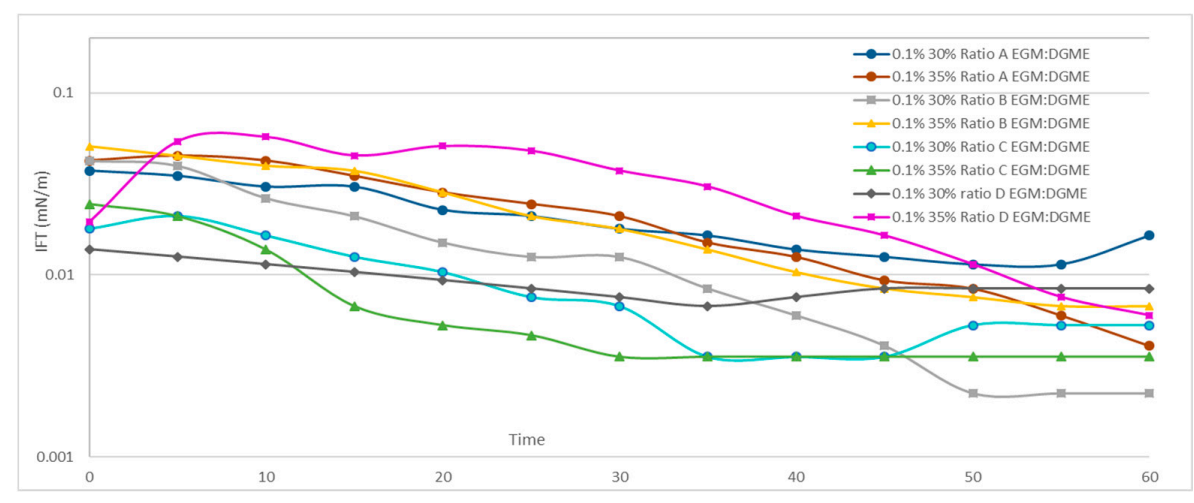

Figure 7. Dynamic IFT for as-synthesized surfactant in the presence of EGME/DGME at different ratio.

\subsection{Microemulsion Phase Behavior Test on As-Synthesized Surfactant with a Co-Solvent Mixture}

Surfactant solution phase behavior is usually influenced by the presence of electrolytes in brine. In EOR application, the surfactant's behavior in the presence of oil and electrolyte solutions is among the critical factors determining the effectiveness of the solution when injected into the reservoir [25]. The phase behavior experiment represents the interaction 
between the two phases, nonpolar (oil) and polar (brine/seawater), containing surfactant. The presence of surfactants in these two phase systems leads to a homogenous microemulsion, which is thermodynamically stable and allows light to pass through it $[5,25,26]$. In this test, the selected solvent-surfactant combination with a selected ratio that gives an ultralow IFT value was tested for the phase behavior. A surfactant generally works in optimum salinity to produce microemulsion. At the optimum salinity, the same amount of water and oil is dissolved in the microemulsion phase [27]. In this work, we focused on applying seawater and evaluating the phase behavior of the surfactant at a fixed seawater salinity of 30,000 ppm. Figures 8-10 present the phase behavior of the surfactant with a $35 \mathrm{wt} . \%$ mixture of co-solvents at different ratios (ratios B, C, and D) mixed with actual reservoir crude oil after 14 days of exposure at reservoir temperature.

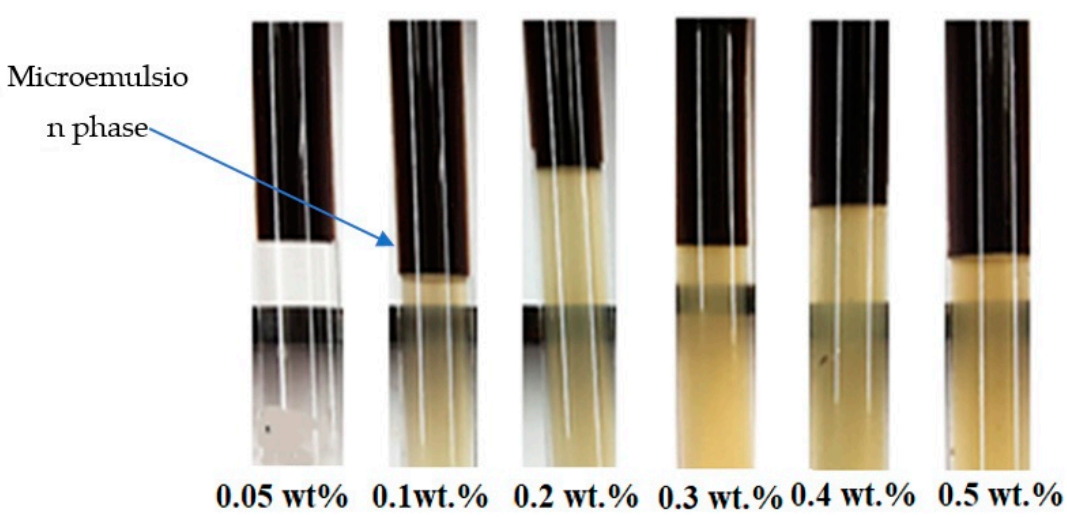

Figure 8. Phase behavior of as-synthesized surfactant with 35 wt.\% co-solvent mixture at different concentrations in ratio $\mathrm{B}(3: 1)$.
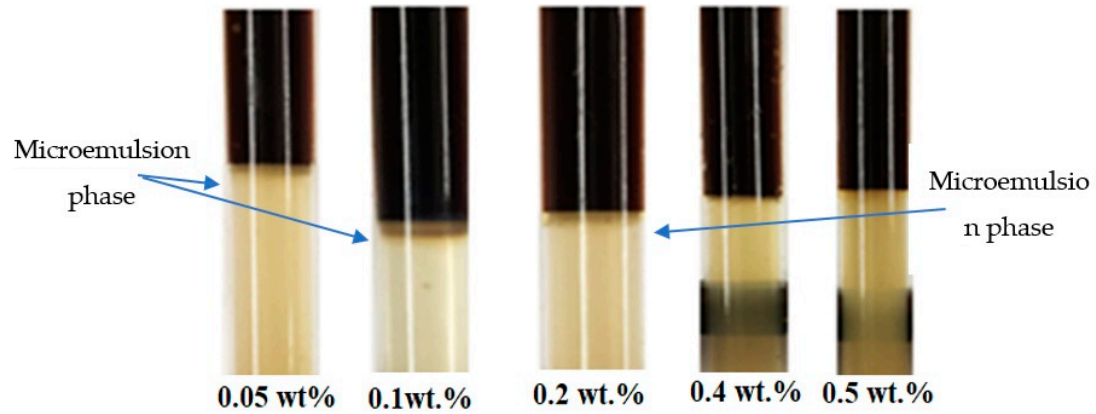

Figure 9. Phase behavior of as-synthesized surfactant with $35 \mathrm{wt} . \%$ co-solvent mixture at different concentrations in ratio $\mathrm{C}(4: 1)$.

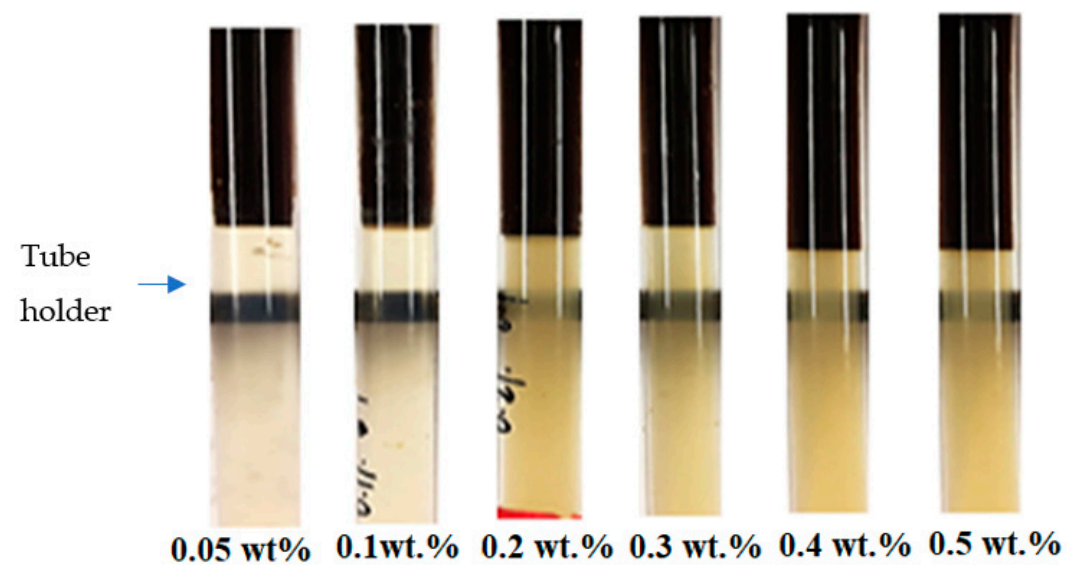

Figure 10. Phase behavior of the as-synthesized surfactant with $35 \mathrm{wt} . \%$ co-solvent mixture at different concentrations in ratio $\mathrm{D}(6: 1)$. 
Figure 8 represents the as-synthesized surfactant in the presence of a co-solvent mixture in ratio B (3:1), in which the concentration has been varied from 0.05 to $0.5 \mathrm{wt} \%$. A thin layer of middle-phase microemulsion (Winsor type III), which can also be considered as a boundary between type I and type III, was observed at the surfactant concentration of $0.1 \mathrm{wt}$ \%. However, the other surfactant concentrations from 0.2 to $0.5 \mathrm{wt}$. \% show the behavior of Winsor type I microemulsion, where only two phases of oil in water exist. This type of phase behavior can usually be seen in low-salinity brine in a salinity gradient test [28].

Figure 9 shows the phase behavior of the surfactant in a co-solvent mixture with ratio C (4:1). This ratio contains more EGME compared to ratio B (3:1), while the amount of DGME was fixed. There is clear evidence of Winsor type III microemulsion, which can be seen at this ratio for the concentrations of 0.05 to $0.2 \mathrm{wt} \%$, in which the upper and lower layer contain the oil phase and seawater, respectively. In contrast, the middle phase consists of oil, surfactant, and co-solvent mixture [29]. However, a clear lower layer and no middle phase were observed for $0.05 \mathrm{wt}$.\% concentration, which indicated that the concentration of surfactant is not enough to make it stay in the aqueous phase and partition to the middle layer, thus forming type II phase behavior [30]. From this phase behavior finding, it was proven that the type III microemulsion, which is desirable for chemical EOR, can be formed at a certain concentration of surfactant in a fixed salinity provided that the structure of the surfactant and the balance between the hydrophobicity and hydrophilicity of surfactant and co-solvent moieties are matched with the crude oil in the study [26,31].

Figure 10 exhibits the phase behavior of the surfactant with ratio D. There was no Winsor type III behavior observed from the sample but there was behavior of type II, which was shown by the 0.05 and $0.1 \mathrm{wt}$ \% surfactants. Meanwhile, the rest of the samples from 0.2 to $0.5 \mathrm{wt}$.\% showed the behavior of type I, where the upper oil layer exists in equilibrium with the lower $(o / w)$ microemulsion phase [32]. This combination has the highest amount of ratio EGME to DGME. More EGME added to the system increases the hydrophilicity, resulting in more surfactant dissolved into the brine layer instead of the oleic phase. This combination generated the highest dynamic IFT in the magnitude of $10^{-1} \mathrm{mN} / \mathrm{m}$ at early contact with crude oil but reduced to the magnitude of $10^{-3} \mathrm{mN} / \mathrm{m}$, indicating an ultra-low IFT value at the end of the $60 \mathrm{~min}$.

\section{Conclusions}

The instability of the dynamic IFT and slightly cloudy appearance of as-synthesized oleic amido propyl betaine surfactant mixture with a long hydrophobic tail can be improved by adding EGME and DGME. The appearance issue needs to be solved before it can be applied in EOR, even though it exhibits the desired ultra-low IFT value. The two types of co-solvent successfully provided the surfactant with the additional polar group desired for the hydrophilicity of the surfactant. The findings showed that EGME in a single application successfully improved the appearance while still maintaining the ultra-low IFT property of the surfactant with a minimum of $30 \mathrm{wt}$ \% application. DGME exhibited better improvement in the solubility with slight surface activity changes in the interface, which can be seen in the increment in IFT value to $10^{-2} \mathrm{mN} / \mathrm{m}$ magnitude. On the other hand, the mixture of this co-solvent based on the ratio method indicated that the combination of these co-solvents contributed to a better interface activity by lowering the IFT down to an ultra-low level as compared to the application of a single co-solvent. Additionally, Winsor type III microemulsion phase behavior can be seen clearly at concentrations from 0.05 to $0.1 \mathrm{wt}$ \% in the presence of co-solvent mixtures at a ratio of $4: 1$ (ratio C) with $35 \mathrm{wt}$ \% (EGME to DGME). These results confirmed that the presence of the co-solvent in formulation mixtures could alter the behavior of the as-synthesized surfactant regardless of the fixed salinity of seawater used and induced packing adsorption at the interface, resulting in ultra-low IFT between oil and seawater, which makes it possible to evaluate this surfactant further and has the potential to be applied in EOR. 


\begin{abstract}
Author Contributions: Formal analysis, N.A.W.; validation, W.S.; writing-original draft, N.A.W.; supervision, A.R.; writing-review and editing, A.R., W.S. and N.Y. All authors have read and agreed to the published version of the manuscript.
\end{abstract}

Funding: This research received financial support from GR\&T-UTP collaboration (Cost centre-0153 CB-021)

Acknowledgments: The authors acknowledge Farah Nabilah Shafie, Intan Khalida Salleh and Arif Azhan b Abd Manaf from Petronas Research Sdn Bhd for their contribution to proofreading the article and technical discussions.

Conflicts of Interest: The authors declare no conflict of interest.

\title{
References
}

1. Zhou, Z.-H.; Zhang, Q.; Liu, Y.; Wang, H.-Z.; Cai, H.-Y.; Zhang, F.; Tian, M.-Z.; Liu, Z.-Y.; Zhang, L.; Zhang, L. Effect of Fatty Acids on Interfacial Tensions of Novel Sulfobetaines Solutions. Energy Fuels 2014, 28, 1020-1027. [CrossRef]

2. Nagy, R.; Sallai, R.; Bartha, L.; Vágó, Á. Selection Method of Surfactants for Chemical Enhanced Oil Recovery. Adv. Chem. Eng. Sci. 2015, 5, 121-128. [CrossRef]

3. Chen, S.; Liu, H.; Sun, H.; Yan, X.; Wang, G.; Zhou, Y.; Zhang, J. Synthesis and physiochemical performance evaluation of novel sulphobetaine zwitterionic surfactants from lignin for enhanced oil recovery. J. Mol. Liq. 2018, 249, 73-82. [CrossRef]

4. Saki, M.; Reza, A. Influence of Surfactant Type, Surfactant Concentration, and Salinity on Interfacial Tension of a Brine/Live Oil/Surfactant Fluid System: A Case Study of Iranian Asmari Oil Reservoir. Iran. J. Oil Gas Sci. Technol. 2017, 6, 1-12.

5. Kamal, M.S.; Hussein, I.A.; Sultan, A.S. Review on Surfactant Flooding: Phase Behavior, Retention, IFT, and Field Applications. Energy Fuels 2017, 31, 7701-7720. [CrossRef]

6. Wang, D.; Liu, C.; Wu, W.; Wang, G. SPE 127452 Novel Surfactants that Attain Ultra-Low Interfacial Tension between Oil and High Salinity Formation Water without adding Alkali, Salts, Co-surfactants, Alcohol and Solvents Conditions for surfactants to attain ultra-low IFT at low concentrate. SPE Asia Pacific Enhanc. Oil Recover. Conf. 2010. [CrossRef]

7. Wazir, N.A.; Ramli, A.; Yusof, N.M.; Saphanuchart, W.; Majanun, E.S. As-Synthesized Oleic Amido Propyl Betaine Surfactant Mixture and the Effect on the Crude Oil-Seawater Interfacial Tension. Processes 2020, 8, 965. [CrossRef]

8. Liang, X.; Xiang, M.H.; Yang, Y.; Chen, Q.H.; Shu, Z.R. The Laboratory Research on Ultra-Low Interfacial Tension Foam Flooding System with High-Temperature and High-Salinity. Appl. Mech. Mater. 2011, 71, 2163-2168. [CrossRef]

9. Sahni, V.; Dean, R.M.; Britton, C.; Kim, D.H.; Weerasooriya, U.; Pope, G.A. The role of co-solvents and co-surfactants in making chemical floods robust. Proc. SPE Symp. Improv. Oil Recovery 2010, 2, 1515-1532.

10. Dwarakanath, V.; Chaturvedi, T.; Jackson, A.; Malik, T.; Siregar, A.A.; Zhao, P. Using co-solvents to provide gradients and improve oil recovery during chemical flooding in a light oil reservoir. SPE Symp. Improv. Oil Recovery 2008, 3, 1292-1303. [CrossRef]

11. Upamali, K.A.N.; Liyanage, P.J.; Cai, J.; Lu, J.; Jang, S.H.; Weerasooriya, U.P.; Pope, G.A. New Surfactants and Co-Solvents Increase Oil Recovery and Reduce Cost. SPE Improv. Oil Recovery Conf. 2016, 23, 2202-2217. [CrossRef]

12. Dong, Z.; Wang, X.; Liu, Z.; Xu, B.; Zhao, J. Synthesis and physic-chemical properties of anion-nonionic surfactants under the influence of alkali/salt. Colloids Surfaces A Physicochem. Eng. Asp. 2013, 419, 233-237. [CrossRef]

13. Negin, C.; Ali, S.; Xie, Q. Most common surfactants employed in chemical enhanced oil recovery. Petroleum $2017,3,197-211$. [CrossRef]

14. Tristantini, D.; Hakim, H.P.; Zuliardy, M.F. Addition of egbe and ethanol to enhance mes performance as chemical flooding material. J. Tek. Kim. Indones. 2018, 10, 120-126. [CrossRef]

15. Chew, C.H.; Gan, L.M.; Koh, L.L.; Wong, M.K. Microemulsion systems with monobutyl ether of ethylene glycol or diethylene glycol as cosurfactant. J. Dispers. Sci. Technol. 1988, 9, 37-41. [CrossRef]

16. Novriansyah, A.; Bae, W.; Park, C.; Permadi, A.K.; Riswati, S.S. Optimal Design of Alkaline-Surfactant—Polymer Flooding under Low Salinity Environment. Polymers 2020, 12, 626. [CrossRef]

17. Czajka, A.; Hazell, G.; Eastoe, J. Surfactants at the Design Limit. Langmuir 2015, 31, 8205-8217. [CrossRef]

18. Araújo, A.A.D.L.; Federal University of Rio Grande do Norte; Neto, E.L.D.B.; Chiavone-Filho, O.; Foletto, E.L. Federal University of Santa Maria Influence of sodium chloride on the cloud point of polyethoxylate surfactants and estimation of Flory-Huggins model parameters. Rev. Fac. Ing. Univ. Antioq. 2015, 1, 155-162. [CrossRef]

19. Zhao, J.; Dai, C.; Ding, Q.; Du, M.; Feng, H.; Wei, Z.; Chen, A.; Zhao, M. The structure effect on the surface and interfacial properties of zwitterionic sulfobetaine surfactants for enhanced oil recovery. RSC Adv. 2015, 5, 13993-14001. [CrossRef]

20. Diamant, H.; Andelman, D. Kinetics of Surfactant Adsorption at Fluid-Fluid Interfaces. arXiv 1996, arXiv:cond-mat/9608140v1. [CrossRef]

21. Hutin, A. Dynamic Adsorption of Surfactants at Air/Water Interface. Available online: https://www.researchgate.net/ publication/331327676 (accessed on 22 December 2020).

22. Chawla, R.; Doura, K.; McKay, D. Effect of alcohol cosolvents on the aqueous solubility of trichloroethylene. In Proceedings of the 2001 Conference on Environmental Research, Manhattan, KA, USA, 21-24 May 2001; pp. 52-66. 
23. Gil, P.S.; Lacks, D.J.; Gil, P.S.; Lacks, D.J. Effect of surfactant shape on solvophobicity and surface activity in alcohol-water systems. J. Chem. Phys. 2016, 145, 204705. [CrossRef] [PubMed]

24. Sheng, J.J. Status of surfactant EOR technology. Petroleum 2015, 1, 97-105. [CrossRef]

25. Yarveicy, H.; Haghtalab, A. Effect of amphoteric surfactant on phase behavior of hydrocarbon-electrolyte-water system-an application in enhanced oil recovery. J. Dispers. Sci. Technol. 2017, 39, 522-530. [CrossRef]

26. Piispanen, P.S. Synthesis and Characterization of Surfactants Based on Natural Products. Diss. Kimi 2002.

27. Beygi, M.R.; Varavei, A.; Lotfollahi, M.; Delshad, M. Low-Tension Gas Modeling in Surfactant Alternating Gas and Surfactant/Gas Coinjection Processes. In Proceedings of the SPE Asia Pacific Enhanced Oil Recovery Conference, Kuala Lumpur, Malaysia, 11-13 August 2015; pp. 1-16.

28. Elmofty, O. Surfactant Enhanced Oil Recovery by Wettability Alteration in Sandstone Reservoirs. Master's Thesis, Geosciences and Geological and Petroleum Engineering, Missouri S\&T, Rolla, MO, USA, 2012.

29. Pal, N.; Kumar, S.; Bera, A.; Mandal, A. Phase behaviour and characterization of microemulsion stabilized by a novel synthesized surfactant: Implications for enhanced oil recovery. Fuel 2019, 235, 995-1009. [CrossRef]

30. Kamal, M.S.; Sultan, A.S.; Hussein, I.A. Screening of amphoteric and anionic surfactants for cEOR applications using a novel approach. Colloids Surfaces A Physicochem. Eng. Asp. 2015, 476, 17-23. [CrossRef]

31. Song, B.; Hu, X.; Shui, X.; Cui, Z.; Wang, Z. A new type of renewable surfactants for enhanced oil recovery: Dialkylpolyoxyethylene ether methyl carboxyl betaines. Colloids Surfaces A Physicochem. Eng. Asp. 2016, 489, 433-440. [CrossRef]

32. Kale, S.N.; Deore, S.L. Emulsion Micro Emulsion and Nano Emulsion: A Review. Syst. Rev. Pharm. 2016, 8, 39-47. [CrossRef] 